\title{
Stewardship of Digital Archaeological Data in Greece: a landscape of fragmentation
}

\author{
Despoina Tsiafaki and Markos Katsianis
}

\section{Summary}

This article provides an overview of the current situation in Greece regarding digital archaeological data stewardship. A brief chronicle of Greek archaeology sets the scene for a better understanding of the present situation. Greek archaeology is supervised by the Ministry of Culture and Sports, with the Archaeological Service as the central organisation in charge of antiquities. However, archaeological data resulting from archaeological fieldwork are produced by several other entities. This article presents the policies governing both physical and digital documentation archives. It introduces the current practices for archaeological data preservation and the relevant digital infrastructures, attempting to showcase the existing environment. We categorise prevailing problems on three levels, all based on the fact that digital and open access arrived recently in a well-established environment formed gradually over almost two centuries.

Even so, fragmentation and variation would be the proper terms to describe the status of the stewardship of digital archaeological data in Greece. Our review shows that there is substantial effort directed towards digital archaeological data stewardship and accessibility by all stakeholders within the archaeological sector. Finally, we add a few thoughts and suggestions, and indicate the need to generate a network that could take steps towards more inclusive strategies within digital data stewardship. The key to leveraging change is raising awareness about data sustainability and reuse, and the COVID-19 outbreak indicates a clear change in mentality in this direction, since open access resources have begun to be key to education and research conducted in Greece. 


\section{Introduction}

Greek archaeology falls under the supervision of the Greek Ministry of Culture and Sports. As an independent entity dealing with all the different sectors of tangible and intangible culture from antiquity to the present, it was formed in 1971 as the Ministry of Culture and Sciences. The Ministry functions like an 'umbrella', incorporating all the different units representing multiple cultural fields, including cultural heritage, and is responsible for cultural policies and management (Zorba 2014).

The active interest and care for antiquities and archaeology dates to the 19th century, as early as the 1821-1829 Greek war of independence. The Archaeological Service, in charge of Greek antiquities was founded in 1829, immediately after the establishment of the independent Greek State. The protection of ancient monuments became its principal task, in combination with recording antiquities, aiming primarily to prevent their illicit trafficking. The first relevant legal document (1834) specifically designated all antiquities within the Greek state as the national property of all Greek citizens. This provision remains in force and dictates any decision or legislation regarding archaeological resources. From the 19th century onwards, archaeology in Greece and all pertinent legislation around it, relate to issues of discovery (e.g. excavation), restoration, study, and above all protection. This brief outline describes the present condition as the outcome of a long procedure through subsequent sociopolitical circumstances that formulated archaeological needs and priorities (see Petrakos 1982; Kokkou 2009; Petrakos 2013; Zorba 2014; Gerousi and Vivliodetis n.d.).

The Archaeological Service remains the central organisation in charge of antiquities. Undertaking archaeological fieldwork in Greek territory by any other entity requires official permission and falls under the oversight of the Archaeological Service. The operation, however, of various other associations (e.g. the Archaeological Society of Athens or the Foreign Archaeological Missions), some of which have directed excavations at prominent archaeological sites since the 19th century, has an impact on the stewardship of the archaeological data produced in Greece, both physical and/or digital. The variation in the strategies adopted for archaeological data curation by the different stakeholders has created a 'landscape of fragmentation' in stewardship practices, particularly affecting digital data.

This contribution provides an overview of the current situation in Greece as regards digital archaeological data stewardship. We move from a brief presentation of archaeological conduct in Greece to policies governing both physical and digital documentation archives across the archaeological sector. The current practices for archaeological data preservation and relevant digital infrastructures are then presented, followed by a discussion on data accessibility and digital data management tactics, attempting to showcase the existing environment. Finally, we add a few thoughts and suggestions for raising awareness of the importance of the guidance around the production of digital archaeological data and their maintenance. 


\section{The Organisation of Archaeological Practice in Greece}

The overall responsibility for heritage within the Ministry of Culture and Sports largely falls to two central services, the General Directorate of Antiquities and Cultural Heritage, which oversees the investigation, documentation, preservation, management and overall protection of cultural heritage, and the General Directorate of Restoration, Museums and Technical Works, which cooperates with the former to implement activities regarding conservation, restoration and enhancement interventions on archaeological sites and monuments. Both have further departments with specific chronological coverage (e.g. Byzantine and Post-Byzantine Antiquities) or focus on activities (e.g. illicit trading).

Among these lies the Directorate for the Management of the National Archive of Monuments (DNAM), which compiles and publishes the ongoing catalogues of the Listed Archaeological Sites and Monuments and the Registered Movable Cultural Heritage of Greece. It also holds the Historical Archive of Antiquities and Restorations. The documentation and curation of archaeological data are among DNAM's primary objectives, along with production and diffusion of guidelines and standards. This special role extends to the coordination of digitisation, digital curation and dissemination activities.

The lower levels comprise the regional divisions or ephorates of antiquities, which divide the Greek territory into several areas of archaeological responsibility that roughly match that of the administrative division of the country into Prefectures (see also Benissi 2014).

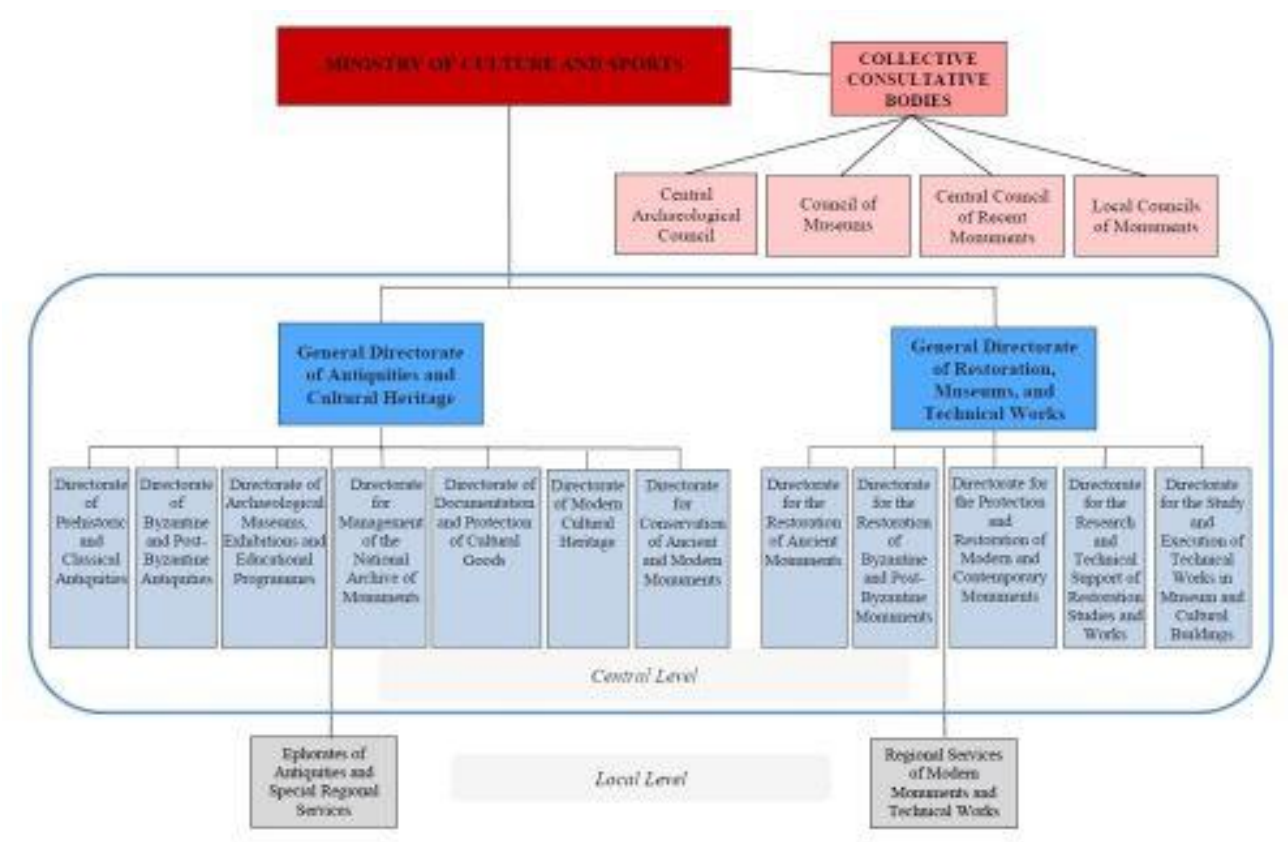

Figure 1: The institutional framework of the Ministry of Culture and Sports (after https://www.coe.int/en/web/herein-system/greece)

However, archaeological fieldwork and data production results from various entities, many of which are external to the Ministry of Culture and Sports (Benissi 2014, 
IHC 2014, 28-39). In general, the archaeological sector can be divided into five separate groups or stakeholders producing archaeological data requiring stewardship:

1. The State Ephorates of Antiquities

2. Museums (different status applies - e.g. public/private/mixed management)

3. Universities and Research Institutes that specialise in archaeological or palaeontological research

4. Foreign Archaeological Missions, also known as 'Schools'1

5. Other societies, e.g. the Archaeological Society at Athens

All these groups have conducted archaeological fieldwork (mainly systematic excavations) and since the 19th century have held both physical collections and documentation. Except for the first group and some of the museums in the second group, the remainder are not directly dependent upon the Ministry of Culture and Sports. They largely follow their own practices for the recording, documentation, presentation, and preservation of their archaeological data in physical or digital formats. Our presentation of the current situation of archaeological data stewardship employs this distinction.

\section{Physical Documentary Archives}

As a result of the decentralised organisation of the Archaeological Service, each of the several local ephorates and museums is responsible for documenting archaeological interventions and managing the respective material. Evidence from 19th- and 20thcentury excavations are either deposited in the Archive of the Archaeological Service managed by DNAM or remains dispersed among the archaeological ephorates (Alexandri 2011). The enduring lack of standardised archaeological documentation guidelines for conducting archaeological interventions has resulted in very diverse physical documentary archives. Their public accessibility, albeit relatively recent, is an ever-growing demand.?

The archaeological law 3028/2002 (Official Government Gazette - OGG 153 A/28.6.2002), with the recent additions of law 4708/2020 (OGG A 140/21.7.2020) and the Presidential Decree that describes the responsibilities of the Greek Ministry of Culture and Sports (OGG A 7/22.1.2018), regulates to a substantive extent the responsibilities of project supervisors with regard to fieldwork documentation, excavation study and publication ${ }^{3}$. More specifically, project supervisors in all sectors are obliged to deposit annual reports and catalogues of finds, while final publications should be prepared within specific time limits according to the type of archaeological intervention. This ranges from two years (survey) to twelve years (maritime/underwater interventions). For the duration of this period, the project supervisor has exclusive rights to the documentation produced and the resulting publications.

Afterwards, the entire original documentation material (in the case of rescue excavations), or a full copy of the documentation material (in the case of systematic research programs such as excavation/survey) should be deposited with the Archaeological Service (Pantos 2013). Documentation material can be accessed following requests to the respective body that holds the archive (e.g. DNAM). However, the general impression is that these provisions are not always met in practice and in many cases fieldwork documentation material with exclusive access rights is kept by the 
project coordinator, largely due to the persistence of customary ethics practices (Canellopoulou-Boti et al. 2013, 4-5; Kakavogianni and Gikaki 2016).

The indirect consequence of the above is the likely existence of numerous dispersed archives with archaeological data, the majority of which are not digital. This is either because they were created in the pre-digital era (and remain undigitised) or they were (and perhaps still are) intentionally produced in print for conventional cataloguing procedures. An estimated distribution of primary original physical documentary archives indicates that:

- Each central or regional state service maintains some form of internal archival documentation.

- Museums sustain their own material and, in some cases, hold the archives of the respective ephorate projects.

- Documentation archives from university research are normally hosted internally. However, usually no centralised storage is available, and records are accommodated by individual archaeological research projects in their respective facilities. Essentially, each project supervisor is responsible for maintaining their own archives as part of their production or curation practices.

- Foreign Archaeological Schools manage their own assets and, in most cases, they have their own archiving facilities and collections.

- Finally, the work by other societies is likewise stored within in-house facilities.

To these, a considerable number of 'private' or 'personal' archives should be added, especially from earlier generations of archaeological scholars or professionals. These could contain handwritten notes, sketches and even photographs or films.

\section{Digital Documentary Archives}

In the last twenty years EU funding in the context of the Operational Programmes 'Information Society' (2000-2006), Digital Conversion (2007-2013) and Competitiveness, Entrepreneurship and Innovation (2014-2020) allowed a massive focus on digitising cultural heritage (Foka et al. 2017). In this context, effort was directed towards setting up content aggregating infrastructures as well as guidelines and good practices for digitisation procedures, metadata documentation and long-term preservation of digital cultural heritage (e.g. LHPIS 2003; Digitech III 2004; Vasilogamvrakis and Bartzi 2015; Stathopoulos et al. 2013). In the same period the ever-growing penetration of digital methodologies in almost all aspects of archaeological research resulted in an increasing amount of born-digital, digitised or digitally enhanced archaeological fieldwork data (e.g. Tsiafaki et al. 2004; Bevan and Conolly 2012; Katsianis et al. 2015; Pakkanen 2018; Giagkoudi et al. 2018). This has resulted in investment in digital data production and management workflows across the archaeological sector at the levels both of entire organisations or individual projects.

However, due to the very recent expansion of digital documentation practices, the archaeological legislation has not as yet managed to include any specific provisions in respect of born-digital or digitised content. Therefore, the landscape of practices regarding digital data stewardship remains largely unregulated. The appropriate use of digital procedures for data capture and data management, as well as guidelines regarding the sustainable deposition of archaeological datasets to institutional or 
thematic repositories, seems to rest largely with internal organisational policies and individual project strategies.

\section{Data Repositories and Current Practices for Archaeological Data Preservation in Greece}

In this context, there are several different types of digital infrastructures that currently contain archaeological information or at least the potential to do so. These are presented according to the stakeholder groups listed in the previous section followed by a brief account of recent developments.

\subsection{State archaeology}

Starting with the state archaeology, digital data management and dissemination infrastructures have so far been explored mainly by the DNAM under activities targeting the nationwide recording, documentation and management of archaeological collections and monuments. Three major projects have been pursued in the past 20

years: : Polemon (Bekiari et al. 1999; DNAM 2008), an integrated information system of moveable monuments aiming to combine documentation for portable finds in museum and state archaeological collections, the Archaeological Cadastre, which defines and maps existing archaeological areas and landscapes owned or supervised by the Greek Ministry of Culture and Sports, and Polydefkis, a structured, controlled thesaurus for cultural heritage (Doerr and Kalomirakis 2000; Kalomirakis and Pantou 2011). All these projects have undergone several cycles of subsequent development, thus manifesting the complexities of top-down approaches to the digital management of archaeological assets. Very recently (April 2021), the web portal of the Digital Collections of Moveable Monuments of the Ministry of Culture and Sports was launched, while the web portal of the Archaeological Cadastre has been delivered directly to the pilot partners (e.g. coresponsible Ministries) and is scheduled to be publicly available by summer 2021 . The former incorporates portions of the resources originally aggregated in the framework of Polemon and includes parts of the vocabularies developed under Polydefkis.

Several other thematic inventories for internal use are maintained by various central and regional divisions (e.g. Digital Collections, Catalogue of Modern and Contemporary Monuments, Catalogue of Underwater Archaeological Sites) (Benissi 2014, 15-16). Certainly, each separate central or regional service of antiquities and museums use their own means and in-house facilities to curate relevant digital records (e.g. Riginos et al. 2008; Tzevreni 2011; Antonopoulos 2011; Agnousiotis and Vouzaxakis 2015). Essentially, the level of data stewardship varies depending on the capacity (time and knowledge) of the staff and the respective infrastructure. In some cases, individual state agencies have investigated available solutions to implement a formal open-access data infrastructure, such as the repository of the Acropolis Restoration Service (ARS) that streamlined their native data management system with export capabilities into public repository structures provided by the National Documentation Centre (NDC), which were then aggregated into SearchCulture (Katsianis 2013; Katsianis and Kamatsos 2017). 


\subsection{Museums}

Museums can be regarded as major cultural content providers, though their actual contribution to what could be described as archaeological datasets (i.e. primary or processed data from archaeological fieldwork) is restricted in Greece. Different solutions have been explored by different types of institutions according to their legal status or perhaps even their thematic focus. Among the variety of examples, we could perhaps showcase three major museums.

The state Museum of Byzantine Culture at Thessaloniki showcases a selection of prominent artefacts organised by material type on its website. This is a solution in use by several museums across Greece and abroad that utilise available Web Content Management Systems (e.g. Drupal) to increase their web presence. The Acropolis Museum, comprising a Legal Entity of Public Law, has recently launched its own web interface to showcase parts of its digital collection currently migrated into a Collections Database (MuseumPlus). Finally, the Benaki museum , one of the first Greek cultural institutions under Private Law, has maintained an information technology department since 1991, closely following developments in digital collection management and participating in several European programs. Museum artefacts are managed through Collections Database programs (e.g. MuseumPlus), with a portion publicly accessible through a web content management system interface (Joomla) that is also discoverable through Europeana.

\subsection{University research}

With respect to the education sector, existing university repositories take the form of open access digital libraries that aggregate and disseminate each university's intellectual production. These can contain grey literature (i.e. under/postgraduate dissertations, academic publications, working papers and technical reports) as well as supplementary research data (e.g. Nemertes etc) ${ }^{5}$. The content of most academic repositories, along with additional digital collections from a wide number of OAI-PMH compatible memory institutions, are aggregated into OpenArchives, a single infrastructure for Greek scientific digital content $\underline{\underline{n}}$, or SearchCulture, the national aggregator for cultural heritage content (also a Europeana data provider $\stackrel{7}{7}$ ), both developed by the National Documentation Centre (NDC). Through a gradual, bottom-up approach to data curation practices, digital repository application development and investment in cloud computing services and infrastructures, the NDC managed to approach content providers using a SaaS (Software as a Service) approach. This resulted in the gradual alignment of the digital content and relevant metadata from enough content providers into the previously mentioned infrastructures (Bartzi et al. 2019).

However, in terms of actual archaeological datasets the situation is very different. In most cases academic researchers maintain their datasets individually, making use of either personal or institutional facilities depending on the nature of their research (e.g. individual university excavation projects). At best, elements of archaeological research are disseminated through dedicated websites or web-portals (e.g. Aristeia, see also Mazarakis Ainian 2017). Similarly, research institutions (e.g. Athena Research Center, Institute of Mediterranean Studies) do not have institutional open access data repositories. Rather they include collections listing individual project datasets that are 
available online as part of project dissemination deliverables (e.g. Arena, $\underline{\text { AtticPOT}}$, see also Tsiafaki and Michailidou 2018).

\subsection{Foreign archaeological schools}

Foreign archaeological schools also manifest diverging data stewardship practices. Numerous initiatives in the recent past have targeted the merging of data collections between institutions that are active in Greek archaeology (Davis 2011). One of the most successful attempts so far has been Chronique des fouilles en ligne/Archaeology of Greece Online, a resource related to grey literature and fieldwork reporting, that has been jointly set up by the French (EfA) and British Schools at Athens (BSA) and recently integrated with Fasti Online as part of the ARIADNEplus project. As a rule, however, foreign schools act as research and education hubs hosting affiliated projects, so even within each institution there are cases where archaeological documentation material from individual research projects is curated separately. Some schools try to tackle the successful combination of different research datasets, such as the Digital Collections of the American School of Classical Studies at Athens (ASCSA), that integrate published and unpublished material from the Institute's archives and the excavation projects of the Athenian Agora and Corinth, or Pragmata, the archive and database of Swedish archaeological research in Greece by the Swedish Institute at Athens (SIA). From a different point of view the Deutsches Archäologisches Institut (DAI) has directed attention towards the integration of archaeological material from different institutional divisions (e.g. DAl Athen) and projects around the world into a single searchable platform, the iDAl.world. However, across all schools there are several research projects that follow their own data management strategies and at best either set up dedicated web-portals to publish their data online or turn to institutional data repositories to host their research data?

\subsection{Other societies}

Even though it is even more difficult to establish meaningful connections than in the other stakeholder groups, the preferred pathway to data stewardship follows the 'repository-as-a-service model' offered by the NDC. In this respect, the most prominent institutions falling under this category, such as the Archaeological Society at

Athens repository or the Academy of Athens digital repository, have managed to curate and disseminate a respectable portion of their archival content individually, and also via SearchCulture.

\subsection{Recent developments}

In this very diverse landscape of repository solutions, a recent game-changing development has been achieved in the framework of the Greek National Plan for Open Science (Athanasiou et al. 2020). HELIX is a joint effort of Athena Research Center and GRNET (National Infrastructures for Research and Technology) to provide a crosssectoral digital ecosystem for data-intensive research storage and support, comprising facilities for handling scientific publications, datasets and digital laboratories. HELIX, in collaboration with HEAL-Link (Hellenic Academic Libraries Link Consortium) are developing HARDMIN a cross-disciplinary research data infrastructure for the Greek scientific community. The combined e-infrastructures of HELIX and HARDMIN can 
incorporate thematic and domain-specific data subsets providing services for data deposition for all archaeological research by state agencies, academia and research institutions, as well as other private or non-profit heritage organisations (Pispiringas et al. 2019).

\section{Data Accessibility and the FAIR Principles}

In comparison to the amount of data that are constantly generated as a result of archaeological projects or relevant research and digitisation-based activities, only a very small fragment is estimated to find its way to a data repository and even less is available that complies with the FAIR principles.

OpenArchives and SearchCulture conform to the Open Archives Initiative - Protocol for Metadata Harvesting (OAI-PMH) and each item in a collection has unique, permanent HTTP URIs. Their metadata schemas are based on the Qualified Dublin Core (DC) metadata schema, extended with elements from several other schemas. The resulting schema is compatible with the Europeana Data Model (EDM), allowing for the selective ingestion of Greek content in the European Digital Library (e.g. the ARS repository). Metadata held by both aggregators retain semantic links to their respective vocabularies and thesauri through the provision of the Semantics.gr enrichment tool, that allows the mapping of vocabulary terms used in metadata to thesauri and linked data values (Georgiadis et al. 2016). Finally, with respect to Access Rights, Creative Commons Licences are preferred, though a variety of choices are used by content providers?

HEAL-Link and HELIX, in their effort to adhere to open science principles and maintain compatibility with larger EU infrastructures such as the European Open Science Cloud (EOSC), propose specific data lifecycle guidelines that identify the necessary steps for research datasets to be included in the HARDMIN repository, taking into account the FAIR (Findable, Accessible, Interoperable and Reusable) principles. The actual data catalogue is based on CKAN, an open data publishing solution following the DataCite Metadata Schema and allowing the further support of domain specific metadata schemas. The catalogue provides persistent identifiers to individually added resources and supports data harvesting from OAI-PM and OGC (Open Geospatial Consortium) compatible repositories (Pispiringas et al. 2019). Currently, no archaeological datasets have been incorporated into the respective platforms, though pilot data depositions are currently underway.

Repository facilities from foreign institutions, such as the iDAI.world system, are built on similar Open Science mandates, encouraging open access strategies for its research and data publications $\stackrel{10}{ }$. Other examples of databases or data repositories (e.g. Pragmata, ASCSA.net) have tried to map part of their structures to Dublin Core to facilitate a degree of interoperability, but do not provide persistent identifiers, thus remaining, at best, institutional repositories.

Finally, with respect to state-owned archaeological resources, their accessibility remains fairly limited. Despite the stated commitment to include cultural information within open government data sources in the second (2014-2016) and third (2016-2018) National Action Plan on Open Government (MARE 2014, 16-17; Routzouni et al. 2016, 32-33), 
information created as part of the major digital infrastructure development projects by the Ministry of Culture and Sports is currently largely accessible as an internal resource (Bouras and Routzouni 2018, 56-59; IRM 2019, 33-34). The commitment to provide open access to cultural assets has been reaffirmed in the current fourth (2019-2021) plan, targeting data homogenisation and updates, alongside decisions on data licensing (MAR 2019, 35-36).

\section{Governing Policies in Digital Archaeological Data Management}

The governing environment with respect to archaeological data preservation and open access is not strictly regulated. Based on the known evidence, there are no prescribed guidelines for open access data management as there are in other countries (cf. Guides to Good Practice). With respect to research projects, funding bodies in Greece do not demand Data Management Plans (DMPs), despite an increasing interest in supporting open access to research data as part of project strategy and deliverables.

With respect to open access, law 4305/2014 (OGG 237/A 31-10-2014) mandates the open by default dissemination of public sector information. Its implementation directives include specifications for data formats and expected dataset structures, and all public organisations have categorised and prioritised sets of data to be made publicly

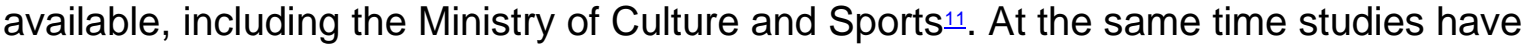
been prepared on the quality of datasets included in the data.gov.gr portal

(Alexopoulos et al. 2018). Further initiatives in the framework of OpenAIRE have resulted in the recent National Plan for Open Science (Athanasiou et al. 2020) that outlines the necessary steps and relevant infrastructure development actions to support the adoption of Open Science in Greece.

Concerning EU policies, the EU recommendation on access to and preservation of scientific information (EU2018/790), and the EU directive on open data and the reuse of public sector information (EU2019/1024) provide a much-needed policy regulation incentive, even if they have not yet been implemented in Greek legislation. Further incentives have been given to member states through the revised version of the Horizon 2020 guidelines that require the inclusion of data management plans and open access to research data in funding applications ${ }^{12}$.

\section{Discussion: Evaluation of the Landscape of Current Practices for Digital Data Preservation}

Despite convergent efforts in recent decades to make digital data survival a central concern in current archaeological research in Greece, a concrete framework that would encourage archaeologists to plan ahead and think about the long-term longevity and dissemination of their digital production is still in development. 
As a result, most professionals make the decision whether or not to implement DMPs and adhere to Open Science principles based on their own capacity and personal willingness. This overview makes evident that the majority of archaeological archives are essentially curated by the project supervisor irrespective of the institutional position (i.e. academic vs state vs foreign school). The integration of Open Science policies seems even more difficult to implement at the institutional level, where completely new workflows that include data management plans and semantic interoperability provisions must be put into effect.

Judging from the landscape of practices described thus far, we would categorise the problems faced as having three levels, all based on the fact that digital and open access arrived recently in a well-established environment formed gradually over almost two centuries. In addition, the lack of financial resources should be added as an issue at all levels.

At the basic level we have identified a shortage of specified or widely known policies that encourage digital data preservation and open dissemination. We tried to demonstrate that there are no common standards or unifying policies across the heritage sector or even within its sub-groupings. This is possibly also related to a lack of incentives to either individual professionals or institutions. Until recently there were no funding provisions with regard to digital data preservation. Both the development and maintenance of repository infrastructures, as well as the required data management plans and respective data-work were not included in research funding. In Greece, where fieldwork funding is in most cases barely adequate to conduct fieldwork, let alone postfieldwork research, digital data management requirements are essentially considered a non-funded side-line, and thus is a time-consuming workflow diverting staff, equipment and administrative resources from actual research.

At the second level there is the problem of insufficient education and expertise to pursue data management. The formulation and execution of data management plans at any level (personal or institutional) requires digital skills and training as well as collaboration with other specialists. The penetration of digital-assisted scholarship and training in university archaeological departments in Greece is still very limited, and most archaeology professionals that employ digital tools in their work have received little, if any, training in aspects of digital data management and preservation (Polymeropoulou et al. 2020). This situation makes moving to an Open Science environment very difficult, especially with the lack of proper guidelines and dedicated staff to administer this transition.

At the third level there is resistance related to current researcher mentalities formed due to previous conditions and objectives. Strupler and Wilkinson (2017) detect the reluctance of archaeologists to adopt Open Science approaches because of risks related to data 'scooping' (i.e. stealing), transparency of data errors, heritage protection concerns and other ethical issues, such as personal data protection. In the Greek case, we feel that all the above are accentuated by an entrenched mentality against 'letting go' of research data for all these reasons. In the past this has resulted in the purposeful delay of publications just to maintain exclusive access rights to material and fieldwork documentation. In the current environment of mixed or exclusively digital data collection in many projects, this has major implications to data longevity and survival. A further problem is related to the lack of sufficient recognition and limited academic credit gained for creating open data. In addition, Koutras (2018) cites earlier surveys and finds that a large number of Greek academics are only partially aware of the Open Access 
Repositories (OARs) concluding that, especially in the Humanities, the benefits of OARs are undervalued. However, judging from our personal academic experience this situation has (especially since the COVID-19 outbreak) changed significantly, rendering open access resources as key to education and research conduct in Greece.

\section{Conclusions: Roadmap of Activities for Raising Awareness}

Fragmentation and variation are the proper terms with which to describe the current situation for the stewardship of digital archaeological data in Greece. Our review shows that there is substantial effort directed toward digital archaeological data stewardship and accessibility by all stakeholders within the archaeological sector, but these efforts are not linked together as well as they should be. We indicate the need to generate a network with representatives from all professional areas and initiate the relevant discussion in Greece. To this end, the active participation of the central archaeological authorities would boost the implementation of these new objectives across the entire spectrum of archaeology in Greece. The wider momentum from international projects such as $\underline{P A R T H E N O S}, \underline{A R I A D N E p l u S}$ and SEADDA can be used to further highlight the issue of data management, and gain from international expertise with regard to data archiving practices and administration, and connect with other countries working to solve similar problems.

It is also encouraging that moves towards Open Science as advocated by EU policies are now reflected in National policies, pushing organisations and individuals to move towards implementing best practice. The respective establishment of Open Science research consortia, funding requirements, data accessibility and reuse indicators can help to provide the necessary incentives for professionals to adopt data management plans and data preservation provisions. Costs involved in depositing datasets should also be regulated across the sector, taking into account open access and data preservation charging provisions (e.g. eligible research funding or developer contribution). A major aid in this regard is the development of HELIX and HARDMIN, which will provide a comprehensive environment for research conduct and data deposition and would work towards infrastructure integration among the different parties.

With respect to education, the incorporation of courses in data curation practices and open science methodologies in archaeological curricula, at both the postgraduate and undergraduate levels, will provide the necessary acclimatisation of the new generation of scholars and professionals to current data stewardship practices and Open Science conduct. This should be tied to greater efforts for pressing issues related to personal archiving, i.e. data collections produced during archaeological interventions in all sectors that remain on outdated hardware, or on hard disk drives that will no doubt become obsolete, especially after the completion of a contract or a career. In this respect, guidelines for good practice, alongside training events, can attract professionals from different backgrounds.

Overall, the organisation of archaeological research data into coherent archives for later study and potential integration into repository facilities should be targeted by all stakeholders within the framework of Open Science in Greece. The key to levering change is raising awareness on those issues relevant to digital data preservation and 
reuse and attempting to build consensus on the best strategies to change mindsets, turn our attention to overlooked digital datasets to preserve, and advocate for the benefits of Open Science.

\title{
Acknowledgements
}

We would like to acknowledge the chair and co-chair of Working Group 1: Stewardship of Archaeological Data, SEADDA (Saving European Archaeology from the digital Dark Age) for the invitation to participate in this special issue. This work was implemented within the framework of SEADDA as part of COST Action 18128, funded by the Horizon 2020 Framework Programme of the European Union.

\section{Footnotes}

1. These comprise dedicated archaeological research institutes or form part of wider cultural missions from different nations in Greece. At present there are 19 Archaeological Schools active in Greece. For a history of their presence in Greece that goes back to the 19th century, see Korka 2007.

\begin{abstract}
2. We should keep in mind that until recently open access was not a requirement. On the contrary, aiming to protect antiquities and prevent their illicit trafficking justifies, to a certain extent, the graded levels of access to research archives. Those archives were principally intended for use by archaeological researchers for the publication of their archaeological investigation. The publications (printed volumes or articles) were publicly disseminated. Furthermore, Informatics arrived in Greece, and in particular Greek archaeology, in the very late 20th century, following Europe and USA (cf. Zorba 2014, 300-22).

3. The archaeological law 3028/2002 is available in English by the BSA (PDF) or WIPO (World Intellectual Property Organization) (PDF). All mentioned laws can be retrieved in Greek using the specified notation at the National Printing House.
\end{abstract}

4. For a brief overview of these and other past activities with respect to digital cultural heritage by the Ministry of Culture and Sports see also Canellopoulou-Boti et al. 2013, 7-11. $\longleftarrow$

5. Evidently, many postgraduate theses in archaeology and cultural heritage include structured digital data corpora upon which the reported research is based. These, however, are seldom deposited in digital format alongside the dissertation. At best, they are included in the form of an appendix that supplements the main text of the dissertation. Potential data reuse is further discouraged by embargo periods, which in Greece can take up to 3 years. $\leftrightarrows$

6. Openarchives.gr has been operating since 2006 and has quickly emerged as the largest web search portal for Greek digital science content. It aggregates collections from 59 scientific bodies containing over 750,226 items [Last accessed: 14 September 2020].

7. SearchCulture.gr comprises perhaps the biggest meta-aggregator of digital cultural heritage content in Greece hosting collections from 66 institutions in the country containing ove 682,362 items [Last accessed: 14 September 2020]. $\longleftarrow$

8. According to a survey by Sheehan (2015) Greece ranked in 7th place in holdings number within tDAR, while a recent search in the ADS (11/8/2020) shows 11 datasets relating to the geographic region of Greece, which is still the largest amount held by the ADS from outside the British Isles. It is interesting to note also that almost no datasets from Greece exist within OpenContext (11/8/2020).

9. E.g. Fair Use License by the ARS, CC BY-NC-SA 4.0 (Attribution-Non Commercial-Share Alike 4.0 International) by the Academy of Athens and BY-NC-ND (Creative Commons Attribution, Non-Commercial, No Derivatives) by the Archaeological Society at Athens. $\leftrightarrows$

10. See https://idai.world/why/open-science [Last accessed: 4 December 2020]. $\longleftarrow$

11. The revised ministerial decision on the open dissemination and further use of documents, information and data of the Ministry of Culture and Sports is available at: https://www.culture.gov.gr/DocLib/synola dedomenon OpenData 280319.pdf [Last accessed: 4 December 2020]. $\longleftarrow$ 


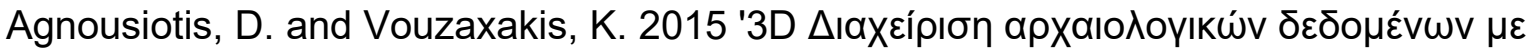

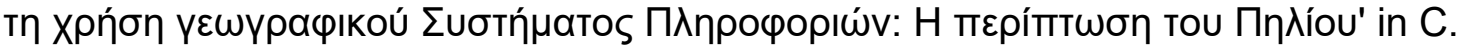
Papadopoulos, E. Paliou, A. Chrysanthi, E. Kotoula, and A. Sarris (eds) Archaeological Research in the Digital Age. Proceedings of the 1st conference on Computer Applications and Quantitative Methods in Archaeology Greek Chapter (CAA-GR). Rethymno, 6-8/3/2014, Rethymno: IMS-FORTH. 105-10.

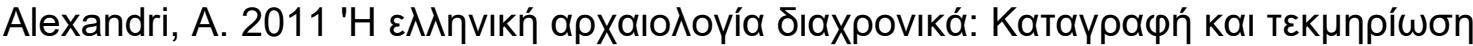

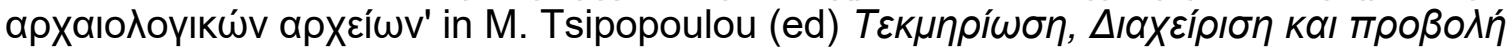

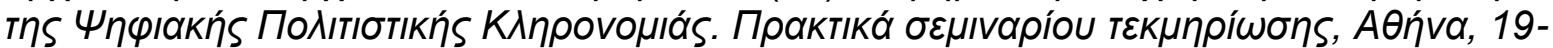
20/2/2010, Athens: Ministry of Culture and Tourism/ Directorate of the National Archive of Monuments, 117-25.

Alexopoulos, C., Loukis, E., Mouzakitis, S., Petychakis, M. and Charalabidis, Y. 2018 'Analysing the characteristics of Open Government data sources in Greece', Journal of the Knowledge Economy 9, 721-53. https://doi.org/10.1007/s13132-015-0298-8

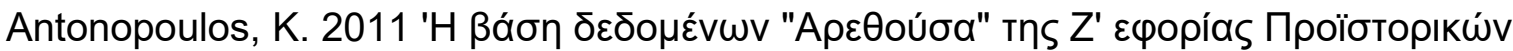

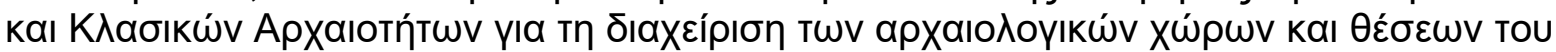

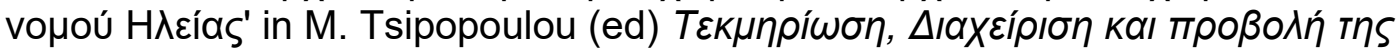

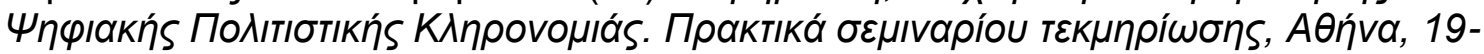
20/2/2010. Athens: Ministry of Culture and Tourism/Directorate of the National Archive of Monuments. 25-34. http://nam.culture.gr/images/deam/docs/Praktika.pdf [Last accessed: 15 September 2020].

Athanasiou, S., Amiridis, V., Gavriilidou, M., Gerasopoulos, E., Dimopoulos, A., Kaklamani, G., Karagiannis, F., Klampanos, I., Kondili, D., Koumantaros, K., Konstantopoulos, P., Lenaki, K., Likiardopoulos, A., Manola, N., Mitropoulou, D., Benardou, A., Boukos, N., Nousias, A., Ntaountaki, M., Oikouta, S., Ollandezou, L., Papadopoulou, E., Papastamatiou, I., Piperidis, S., Speyer, O., Tsiavos, P., Chrysina, E. and Psomopoulos, F. 2020 National Plan for Open

Science. http://doi.org/10.5281/zenodo.3908953

Bartzi, K., Vasilogamvrakis, N., Lagoudi, E., Hardouveli, D. and Sachini, E. 2019 'The Digital Repository Service of the National Documentation Centre in Greece: a model for Digital Humanities data management and representation' in S. Allegreza (ed) 8th AIUCD conference: Pedagogy, Teaching and Research in the Age of Digital Humanities - Book of Abstracts. Udine, Italy, 23-25/1/2019, Associazione per l'Informatica Umanistica e la Cultura Digitale. 65-71. http://hdl.handle.net/10442/16126

Bekiari, Ch., Gritzapi, Ch. and Kalomoirakis, D. 1999 'POLEMON: a Federated Database Management System for the documentation, management and promotion of cultural heritage' in J.A. Barcelo, I. Briz and A. Vila (eds) New Techniques for Old Times. CAA98 - Computer Applications and Quantitative Methods in Archaeology Proceedings of the 26th Conference, Barcelona, March 1998, 317-30. 
Benissi, C. 2014 National Policy Report of Greece, HEREIN

(21/10/2014). https://rm.coe.int/herein-european-heritage-network-greece-nationalpolicy-report/16808c7762 [Last accessed: 15 September 2020].

Bevan, A. and Conolly, J. 2012 'Intensive survey data from Antikythera, Greece', Journal of Open Archaeology Data 1, p.e3. http://doi.org/10.5334/4f3bcb3f7f21d

Bouras, C. and Routzouni, A. 2018 Greece. 3rd National Action Plan on Open Government 2016-2018. End of Term Self-Assessment

Report, https://www.opengovpartnership.org/wp-content/uploads/2018/11/Greece EndTerm Self-Assessment 2016-2018 EN.pdf [Last accessed: 15 September 2020].

Canellopoulou-Boti, M., Vouligea, E. and Sitara, M. 2013 'Avoıктń Про́бßaбп кaı

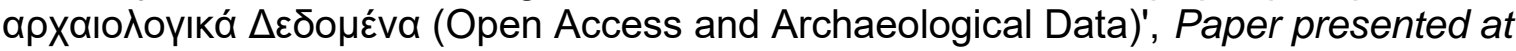
the International Conference on Open Access. EKT. 16-18/10/2013. Presentation available at: http://hdl.handle.net/10442/13589. Text available at:

https://ihrc.gr/download.php?fgr=announcement open access.pdf [Last accessed: 15 September 2020].

Davis, J.L. 2011 The 'Big Digs' Go Digital. Opportunities and Challenges for LargeScale, Multigenerational Excavation Projects in the Digital Age, White paper. http://dx.doi.org/10.17613/M6DH2S

DIGITECH-III 2004 'Study of 3D digitization technologies', Operational Programme Information Society 2004 http://www.ipet.gr/digitech [Last accessed: 4 December 2020].

DNAM (Directorate of the National Archive of Monuments) 2008 'Digitizing the National Collections of Movable Monuments' in M. Tsipopoulou (ed) Proceedings of 'Digital Heritage in the New Knowledge Environment: Shared spaces and open paths to cultural content', Athens: Directorate of the National Archive of Monuments - Ministry of Culture. 190.

Doerr, M. and Kalomirakis, D. 2000 'A metastructure for thesauri in archaeology' in Computing Archaeology for Understanding the Past, Proceedings of the 28th Conference, Lublijana, April 2000, British Archaeol. Rep. International Series 931. 11726.

EU 2018/790 European Commission Recommendation (EU) of 25 April 2018 on access to and preservation of scientific

information. http://data.europa.eu/eli/reco/2018/790/oj [Last accessed: 4 December 2020].

EU 2019/1024 European Commission Directive (EU) of the European Parliament and of the Council of 20 June 2019 on open data and the re-use of public sector information. http://data.europa.eu/eli/dir/2019/1024/oj

Foka, A., Katerelou, A. Kelaidis, K. and Xekalaki, G. 2017 'Digital archaeology? Greece on focus. Tools, methodologies and trends', Archaeology and the Arts https://www.archaeology.wiki/blog/2017/09/19/digital-archaeology-greece-onfocus/ [Last accessed: 4 December 2020]. 
Georgiadis, H., Papanoti, A., Paschou, M. Roubani, A. Pelekanou, D. Chardouveli, D and Sachini, E. 2016 'Semantics.gr: a self-improving service to repositories and aggregators for massively enriching their content', Proceedings of the 10th International Conference on Metadata and Semantics Research, Digital Humanities and Digital Curation (DHC) workshop, Göttingen, Germany, 22-

25/11/2016. http://hdl.handle.net/10442/15420

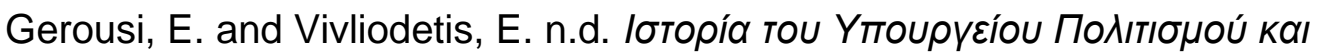

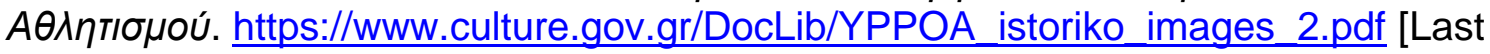
accessed: 4 December 2020].

Giagkoudi, E., Tsiafaki, D. and Papatheodorou, C. 2018 'Describing and revealing the semantics of excavation notebooks' in I. Chrysakis, L. Harami, D. Angelakis and G. Bruseker (eds) CIDOC 2018, Generating and tracing the 'Provenance of Knowledge', Institute of Computer Science, Foundation for Research and Technology Hellas, 29 September-5 October 2018, Heraklion, Crete, Greece. http://network.icom.museum/fileadmin/user upload/minisites/cidoc/Conference Papers/2018/CIDOC2018 paper 71.pdf

IHC (Initiative for Heritage Conservancy) 2014 Discovering the Archaeologists of Greece 2012-14. ISBN 978-618-81517-1-0. https://www.discovering-

archaeologists.eu/national reports/2014/EL\%20DISCO\%202014\%20Greece\%20nation al\%20report\%20english\%20.pdf [Last accessed: 4 December 2020].

IRM (Independent Reporting Mechanism) 2019 Greece End-of-Term Report 20162018 (IRM staff; contributions from A. Melidis, A. Deligiannis and A. Priftis Openwise). https://www.opengovpartnership.org/wpcontent/uploads/2019/06/Greece End-of-Term Report 2016-2018 EN.pdf [Last accessed: 4 December 2020].

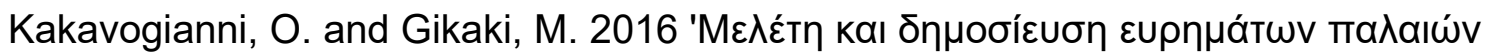

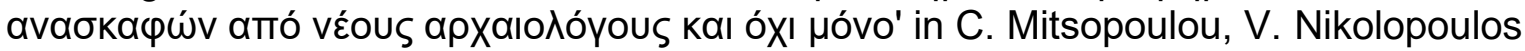

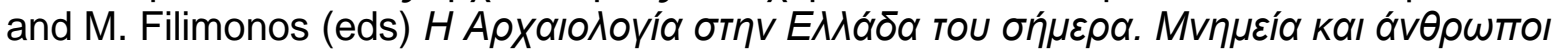

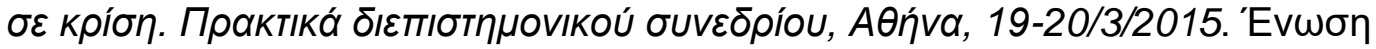

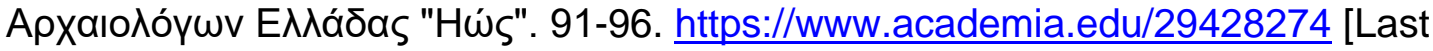
accessed: 4 December 2020].

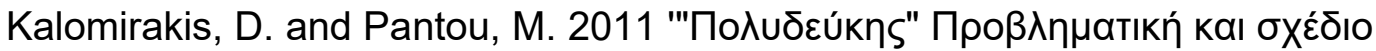

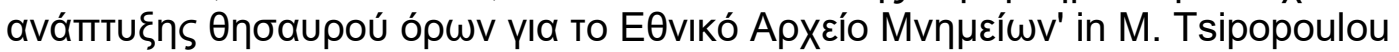

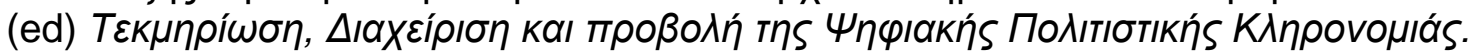

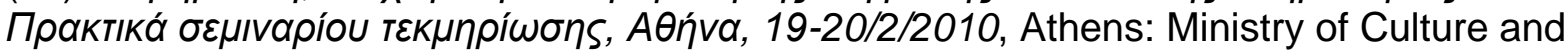
Tourism/ Directorate of the National Archive of Monuments. 251-

74. http://nam.culture.gr/images/deam/docs/Praktika.pdf [Last accessed: 4 December 2020].

Katsianis, M. 2013 'Current challenges in documenting the restoration works on the Acropolis of Athens', The Acropolis Restoration Service Newsletter 13, 20-26.

Katsianis, M. and Kamatsos, P. 2017 'The digital repository of YSMA. Contribution to the preservation of the memory of the restoration interventions', The Acropolis Restoration Service Newsletter 16, 22-26. 
Katsianis, M., Tsipidis, S. and Kalisperakis, I. 2015 'Enhancing excavation archives using 3D spatial technologies' in C. Papadopoulos, E. Paliou, A. Chrysanthi, E. Kotoula, and A. Sarris (eds) Archaeological Research in the Digital Age. Proceedings of the 1st conference on Computer Applications and Quantitative Methods in Archaeology Greek Chapter (CAA-GR). Rethymno, 6-8/3/2014, Rethymno: IMS-FORTH. 46-54.

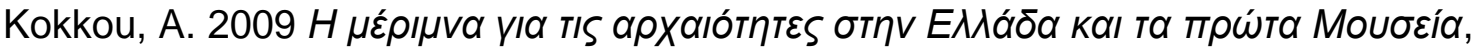
Athens: Kapon.

Korka, E. 2007 Foreign Archaeological Schools in Greece from the 19th to the 21st Century, Athens: Melissa.

Koutras, N. 2018 'The Governance Framework of Open Access Repositories Greece', Seattle Journal for Social Justice 16(2). https://digitalcommons.law.seattleu.edu/sjsj/vol16/iss2/9 [Last accessed: 4 December 2020].

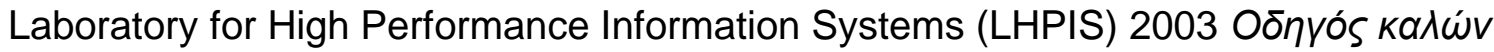

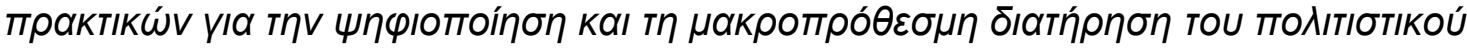

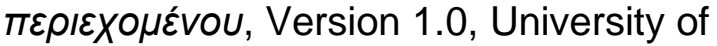

Patras. http://digitization.hpclab.ceid.upatras.gr [Last accessed: 4 December 2020]

Mazarakis Ainian, A. 2017 'The Aristeia Project: the social archaeology of Early Iron Age and Early Archaic Greece' in A. Mazarakis Ainian, A. Alexandridou and X.

Charalambidou (eds) Regional Stories Towards a New Perception of the Early Greek World, University of Thessaly: Volos. 17-34.

MAR (Ministry of Administrative Reconstruction) 2019 4th National Action Plan on Open Government 2019-2021. https://www.opengovpartnership.org/wpcontent/uploads/2019/05/Greece Action-Plan 2019-2021 EN.pdf [Last accessed: 4 December 2020].

MARE (Ministry of Administrative Reform and E-Government) 2014 2nd Greek Action Plan on Open Government 2014-2016 https://www.opengovpartnership.org/wpcontent/uploads/2019/06/Greece-OGP-Action-Plan-2014-2016-eng.pdf [Last accessed: 4 December 2020].

Pakkanen, J. 2018 'Three-dimensional documentation of architecture and archaeology in the field. Combining intensive total station drawing and photogrammetry' in A. Brysbaert, V. Klinkenberg, A. Gutiérrez Garcia-M. and I. Vikatou (eds) Constructing Monuments, Perceiving Monumentality and the Economics of Building: Theoretical and Methodological Approaches to the Built Environment, Leiden: Sidestone Press. 117-40.

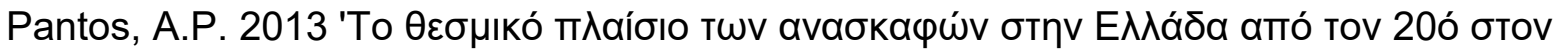
21o aıẃva (The legal framework for the archaeological excavations in Greece: From the

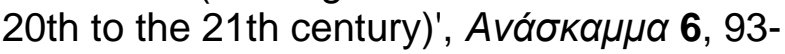

130. https://anaskamma.files.wordpress.com/2013/06/06 pantos.pdf [Last accessed: 4 December 2020].

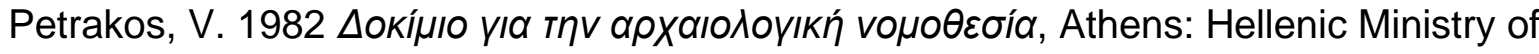
Culture. 


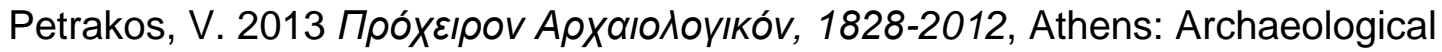
Society at Athens.

Pispiringas, L., Athanasiou, S., Simaioforidis, Z. and Skoutas, D. 2019 'HEAL-Link and HELIX open collaboration to facilitate and promote scholarly communication through Open Access and engage Research Infrastructures in Open Science', 85th IFLA General Conference and Assembly, World Library and Information Congress (IFLA WLIC 2019). http://library.ifla.org/id/eprint/2498

Polymeropoulou, P., Kameas, A., Papadatos, Y., Kalara, A., Sogliani, F., Roubis, D., Vullo, M., Tóth, P., Hons, D., Malíšková, J., Nosek, V. and Pokutta, D. 2020 Training Students in the use of digital technologies in Archaeology. Desk and field research final report, Erasmus+/KA2 project. DELTA: Digital Excavation through Learning and Training in Archaeology. http://www.project-delta.eu/wp-content/uploads/2020/10/DELTA-Deskand-Field-Research Final-Report.pdf [Last accessed: 4 December 2020].

Riginos, G., Drosou, D., Sakkas, D., Vlachopoulou, R. and Liakos, L. 2008 'Record documentation - preservation - promotion. Digital applications of the 33rd Ephorate of Prehistoric and Classical Antiquities for the management of archaeological data' in M. Tsipopoulou (ed) Digital Heritage in the New Knowledge Environment: Shared Spaces and Open Paths to Cultural Content. Proceedings of the International Conference. Athens 30/10-2/11/2008, Athens: Hellenic Ministry of Culture. 44-47.

Routzouni, A., Charalampopoulou, N., Tasiopoulos, S. and Bouras, C. 2016 3rd National Action Plan on Open Government 2016-2018,

27/7/2016. https://www.opengovpartnership.org/wpcontent/uploads/2017/05/GREEK NAP3-OGP-ENG 0 0.pdf [Last accessed: 4 December 2020].

Sheehan, B. 2015 'Comparing digital archaeological repositories: tDAR versus Open Context', Behavioral \& Social Sciences Librarian 34(4), 173-

213, http://dx.doi.org/10.1080/01639269.2015.1096155

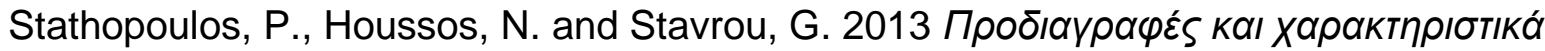

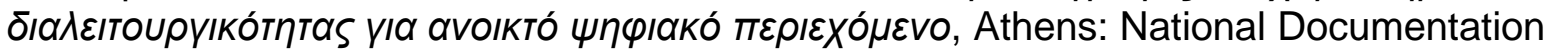
Centre. http://hdl.handle.net/10442/8887

Strupler, N., and Wilkinson, T.C. 2017 'Reproducibility in the field: transparency,version control and collaboration on the Project Panormos Survey', Open Archaeology 3(1), 279304. https://doi.org/10.1515/opar-2017-0019

Tsiafaki, D. and Michailidou, N. 2018 'Ways to cope with the scientific ARENA: taking the results of archaeological research a step further', Proceedings of the 23rd International Conference on Cultural Heritage and New Technologies (CHNT 23). https://www.chnt.at/wp-content/uploads/WSDownload diggingdata.pdf [Last accessed: 4 December 2020].

Tsiafaki, D., Tsirliganis, N., Pavlidis, G., Evangelidis, V. and Chamzas, C. 2004 'Karabournaki - recording the past: digitization of an archaeological site' in V. Cappellini and J. Hemsley (eds) Proceedings of EVA 2004: Conference of Electronic Imaging and the Visual Arts, Florence, 25/3-2/4/2004. Bologna. 232-37. 


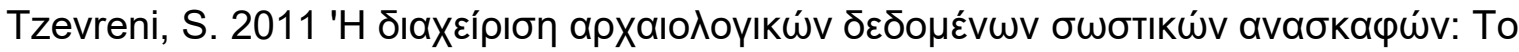

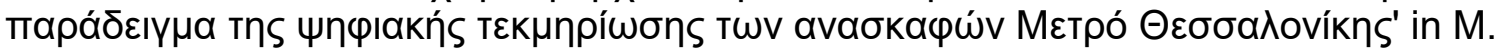

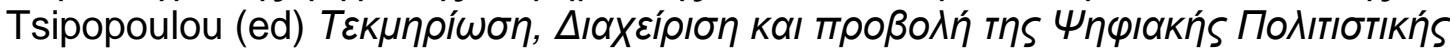

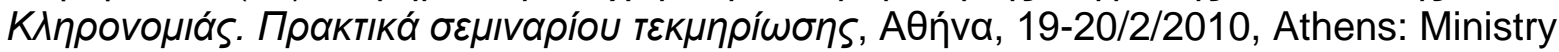
of Culture and Tourism/Directorate of the National Archive of Monuments. 35-

44. http://nam.culture.gr/images/deam/docs/Praktika.pdf [Last accessed: 4 December 2020].

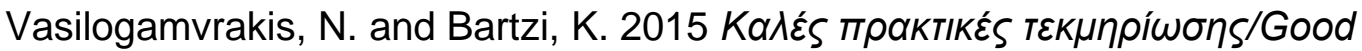
Documentation Practices, Athens: National Documentation

Centre. http://hdl.handle.net/10442/15292

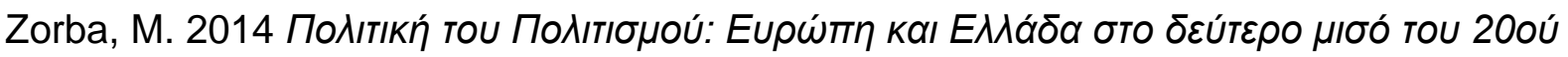
aı́́va, AӨńva: Patakis. 